\title{
Plasma Electrolytic Oxidation in Surface Modification of Metals for Electronics
}

\author{
Mukesh Kumar Sharma*, Youngjoo Jang*, Jongmin Kim**, Hyungtae Kim** and Jae Pil Jung*, \\ *Dept. of Materials Sci. and Eng., University of Seoul, Seoul 130-743, Korea \\ **Apro R\&D Co., Ltd., Seoul 152-769, Korea
}

†Corresponding author : jpjung@uos.ac.kr

(Received May 29, 2014 ; Accepted June 9, 2014)

\begin{abstract}
This paper presents a brief summary on a relatively new plasma aided electrolytic surface treatment process for light metals. A brief discussion regarding the advantages, principle, process parameters and applications of this process is discussed. The process owes its origin to Sluginov who discovered an arc discharge phenomenon in electrolysis in 1880. A similar process was studied and developed by Markov and coworkers in 1970s who successfully deposited an oxide film on aluminium. Several investigation thereafter lead to the establishment of suitable process parameters for deposition of a crystalline oxide film of more than $100 \mu \mathrm{m}$ thickness on the surface of light metals such as aluminium, titanium and magnesium. This process nowadays goes by several names such as plasma electrolytic oxidation (PEO), micro-arc oxidation (MOA), anodic spark deposition (ASD) etc. Several startups and surface treatment companies have taken up the process and deployed it successfully in a range of products, from military grade rifles to common off road sprockets. However, there are certain limitations to this technology such as the formation of an outer porous oxide layer, especially in case of magnesium which displays a Piling Bedworth ratio of less than one and thus an inherent non protective oxide. This can be treated further but adds to the cost of the process. Overall, it can be said the PEO process offers a better solution than the conventional coating processes. It offers advantages considering the fact that he electrolyte used in PEO process is environmental friendly and the temperature control is not as strict as in case of other surface treatment processes.
\end{abstract}

Key Words : Plasma electrolytic oxidation, Micro-arc oxidation, Aluminum, Magnesium, Electronics

\section{Introduction}

Metals such as aluminum, titanium, magnesium etc. possess enormous potential as engineering materials. They have better formability and above all possess good strength to weight ratio in comparison to most other systems. Aluminum is sought after as metal of choice in many cases and is fast replacing structural materials such as steel in many applications. To enhance its properties, aluminum is often coated with a layer of aluminum oxide which resists scratch and corrosion. For long, anodizing was used for growing the layer of oxide. However, since this layer is grown on the surface there is a limit on the life and strength of the adhering oxide layer. A relatively newer process, plasma electrolytic oxidation, provides better surface properties by oxidizing the surface of metal with a uniform oxide film. An oxide layer of $10 \mu \mathrm{m}$ thickness or more can be achieved by this process by modification of the surface itself. A hard and dense scratch free oxide layer along with an excellent surface finish obtained by this process has allowed it to be used in the coating of

This is an Open-Access article distributed under the terms of the Creative Commons Attribution Non-Commercial License(http://creativecommons.org/licenses/by-nc/3.0) which permits unrestricted non-commercial use, distribution, and reproduction in any medium, provided the original work is properly cited. 
consumable electronic goods such as mp3 players, mobile phones etc.. Becerik et. $\mathrm{al}^{1)}$. reported a significant improvement in the corrosion resistance of aluminum by $\mathrm{PEO}$ process. A qualitative comparison of the anodizing and plasma electrolytic oxidation presented in Table 1 brings out the basic difference in the two processes.

Table 1 Comparison of the Anodizing and Plasma Electrolytic Oxidation process

The PEO process was developed more than four decades ago i.e. around 1970s then USSR. Like most other processes, it suffered early setback owing to some technological difficulties such as high voltage requirement and short electrolyte life. These challenges were successfully overcome by consistent effort and the process is now deployed in several applications in automobiles, $\mathrm{RF}$ (radio frequency) repeater, structural materials and machine parts etc.

\section{Principle of Plasma Electrolytic Oxidation}

The plasma electrolytic oxidation process might seem to be an extension of the existing anodizing process where a coating of aluminum oxide is produced on the surface of aluminum by placing the metal to be coated in place of anode. However, the parameters for the two processes vary greatly as discussed in previous section since micro-oxidation channels are established only in the presence of high current density which breaks the dielectric of the oxide while

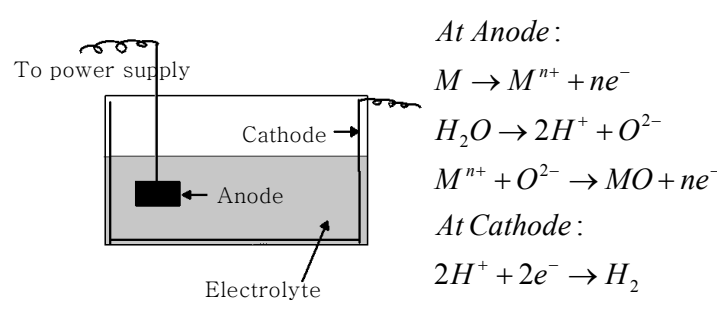

Fig. 1 Schematic of a PEO setup

anodizing is carried out in low current density. It should be noted that a pulsed current with modified amplitude is passed in the electrolyte in case of $\mathrm{PEO}$ process so that a stable corona can be formed. A schematic of the setup for the PEO process is presented in Fig. 1.

The setup essentially involves a power source, the electrolyte and the electrodes. A chiller is attached to lower the temperature of the electrolyte since the plasma formation raises the temperature of the electrolyte. The material whose surface is to be modified is placed as the anode while the container wall is made the cathode. A stainless steel jacket, placed adjacent to the container wall may be used as cathode for the electrolytic oxidation of aluminium. The surface area of finely prepared aluminium sample is measured so as to provide the value for the input current. As soon as the anode is placed in the electrolyte, a very fine natural layer of aluminium oxide is formed, the dimension of which is in nanometer or angstroms. The oxide layer is non-conducting and so a potential difference is built up between the conducting

Table 1 Comparison of the anodizing and plasma electrolytic oxidation process

\begin{tabular}{|c|c|c|}
\hline Property & Anodizing & Plasma Electrolytic Oxidation \\
\hline Cell Voltage & Low $\sim 20-80 \mathrm{~V}$ & High $\sim$ 100-400V \\
\hline Current density & Low $10 \mathrm{~A} / \mathrm{dm}^{2}$ & High $20 \mathrm{~A} / \mathrm{dm}^{2}$ \\
\hline Nature of electrolyte & Acidic, non-Environmental friendly & Alkaline, Environmental friendly \\
\hline Oxide Layer Thickness & Normally $10 \mu \mathrm{m}$ or less & 100 m or more \\
\hline Coating Property & $\begin{array}{c}\text { Moderate hardness and adherence, } \\
\text { low dielectric }\end{array}$ & $\begin{array}{c}\text { High adherence, hardness and dense coating, } \\
\text { high dielectric }\end{array}$ \\
\hline Nature of oxide coating & Amorphous, porous, rougher & $\begin{array}{c}\text { Mostly crystalline, smooth, porous at surface, } \\
\text { dense underneath }\end{array}$ \\
\hline Temperature control of bath & Strict control & Enough to cool the heated electrolyte by a chiller \\
\hline Cost & Higher for hard anodizing & Comparatively Lower \\
\hline
\end{tabular}


electrolyte and the non-conducting oxide. The high potential difference results in the formation of a very high electric field at the very thin electrolyte/oxide region plasma and breaks the dielectric of the oxide. This broken film acts as a pathway for the transport of oxygen to the metal surface resulting in the thickening of the oxide $^{2}$. Similar process happens for the next cycle resulting in the thickening of the oxide layer. Once the desired thickness is reached the process is stopped.

To understand the process, generally, two mechanisms have been proposed regarding the kinetics and growth of the oxide film by $\mathrm{PEO}$ surface treatment. The first mechanism entails the melting of aluminium substrate and subsequent loss of the melt particles in the electrolyte, the melt particles gets oxidized and then settles as thin plate on the aluminium substrate, the plates then grow in a repeated fashion. The second mechanism explains that after the surface of aluminium melts, it is oxidized there itself and the layer grows thereafter by the inward diffusion of oxygen. It is to be noted that a specific set of process parameters are available for different systems since the growth of oxide film by PEO depends on many factors and also that different oxides have different properties.

\section{Parameters affecting the Plasma Electrolytic Oxidation process}

A discernible characteristic of the PEO process is the application of high voltage and current density in comparison to other electrolytic processes such as anodizing. In our trial experiment an aluminum sample with the following configuration was treated by $\mathrm{PEO}$ process. In the process, for an aluminum sample of surface area $50 \mathrm{~cm}^{2}$, a current of $10 \mathrm{~A}$ at $400 \mathrm{~V}$ is needed to make a uniform coating of $10 \mu$. An electrolyte composition of $5 \mathrm{~g} / 1 \mathrm{KOH}$ and $2.5 \mathrm{~g} / 1 \mathrm{Na}_{2} \mathrm{SiO}_{3}$ and a current density of $0.2 \mathrm{~A} / \mathrm{cm}^{2}$ were used for this process. The condition of the sample before and after PEO treatment is shown in Fig. 2.

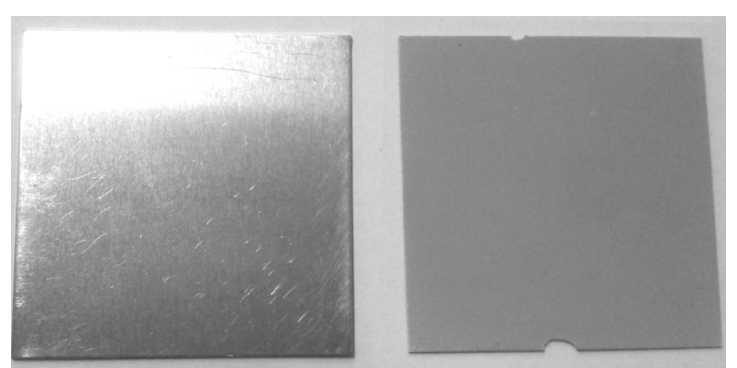

(a)

(b)

Fig. 2 Condition of aluminum sample before and after PEO treatment

The fine finish obtained from PEO treatment is visible in the coated sample, displayed in Fig. 2 (b). Also, it is noted that the lustre of aluminium is lost in the process to a smooth matte finish of aluminium oxide. To obtain a uniform coating of desired thickness it is required to operate under specific process parameters since the process is affected by a number of parameters such as the nature of substrate $^{6.7)}$, composition of electrolyte, additives in electrolyte ${ }^{5)}$, current density, +/- ratio of voltage $^{8)}$ parameters and electrolyte temperature. In a study by Kim et. al. ${ }^{5)}$, different aluminium alloy substrates were used for a PEO test as shown in Table 2. The work reports the effect of substrate composition on the roughness and thickness of developed coating. The basic parameter that is monitored and directly affects the growth of oxide film is the current density ${ }^{8,9)}$. In a study $^{8)}$ regarding the surface modification of magnesium alloys by $\mathrm{PEO}$ treatment it was observed that an increase in current density resulted in a thick coating with lesser number of pores at the surface.

A study of the oxidized surface after PEO treatment revealed that the oxide layer consists of three regions ${ }^{3,4,7)}$ an outer porous oxide film, an intermediate dense oxide layer and an inner thin transition oxide layer. An image of the aluminum oxide coating developed by $\mathrm{PEO}$ process is presented din Fig. 3.

The three layers shown in Fig. 3 are visible under a scanning electron microscope. The "functional 
layer" is a hard, dense coating of the desired thickness. The external layer is morphologically different (high porosity, amorphous) from the

Table 2 Variation in thickness and roughness of coating obtained by PEO process on different aluminium substrates ${ }^{5)}$

\begin{tabular}{|c|c|c|c|c|c|c|c|}
\hline \multirow{2}{*}{\multicolumn{2}{|c|}{$\begin{array}{c}\text { Properties } \\
\text { Time }\end{array}$}} & \multicolumn{3}{|c|}{ Thickness $(\mu \mathrm{m})$} & \multicolumn{3}{|c|}{$\operatorname{Ra} 50(\mu \mathrm{m})$} \\
\hline & & \multicolumn{2}{|c|}{$10 \min$} & $20 \min$ & \multicolumn{2}{|c|}{$10 \mathrm{~min}$} & $20 \min$ \\
\hline \multicolumn{2}{|c|}{ A-1100 } & \multicolumn{2}{|l|}{16} & 21 & \multicolumn{2}{|c|}{1.12} & 1.68 \\
\hline \multicolumn{2}{|c|}{ A-2014 } & \multicolumn{2}{|l|}{13} & 18 & \multicolumn{2}{|c|}{1.02} & 1.03 \\
\hline \multicolumn{2}{|c|}{ A-5052 } & \multicolumn{2}{|l|}{19} & 21 & \multicolumn{2}{|c|}{1.20} & 1.48 \\
\hline \multicolumn{2}{|c|}{ A-6061 } & \multicolumn{2}{|l|}{15} & 18 & \multicolumn{2}{|c|}{1.02} & 1.20 \\
\hline \multicolumn{2}{|c|}{ A-6063 } & \multicolumn{2}{|l|}{14} & 18 & \multicolumn{2}{|c|}{1.09} & 1.84 \\
\hline \multicolumn{2}{|c|}{ A-7075 } & \multicolumn{2}{|l|}{17} & 20 & \multicolumn{2}{|c|}{1.29} & 1.03 \\
\hline \multicolumn{2}{|c|}{$\mathrm{ACD}-7 \mathrm{~B}$} & \multicolumn{2}{|l|}{15} & 19 & \multicolumn{2}{|c|}{1.15} & 2.00 \\
\hline \multicolumn{2}{|c|}{ ACD-12 } & \multicolumn{2}{|l|}{14} & 16 & \multicolumn{2}{|c|}{1.01} & 1.66 \\
\hline \multicolumn{8}{|c|}{ Composition of different aluminum alloys listed above $\mathrm{e}^{5)}$} \\
\hline Alloy & $\mathrm{Mg}$ & $\mathrm{Cu}$ & $\mathrm{Mn}$ & $\mathrm{Cr}$ & $\mathrm{Si}$ & $\mathrm{Zn}$ & $\mathrm{Al}$ \\
\hline A-1100 & - & - & - & - & - & - & $>99.0$ \\
\hline A-2024 & $\begin{array}{l}1.2^{-} \\
1.8\end{array}$ & $\begin{array}{c}3.8^{-} \\
4.9\end{array}$ & $\begin{array}{c}0.3^{-} \\
0.9\end{array}$ & - & - & - & Balance \\
\hline $\mathrm{A}-5052$ & $\begin{array}{l}2.2^{-} \\
2.8 \\
\end{array}$ & - & - & $\begin{array}{l}0.15^{-} \\
0.35 \\
\end{array}$ & - & - & Balance \\
\hline$A-6061$ & $\begin{array}{c}0.8^{-} \\
1.2\end{array}$ & $\begin{array}{c}0.15^{-} \\
0.4\end{array}$ & - & $\begin{array}{c}0.04^{-} \\
0.35\end{array}$ & $\begin{array}{l}0.4^{-} \\
0.8\end{array}$ & - & Balance \\
\hline A-6063 & $\begin{array}{r}0.45- \\
0.9\end{array}$ & - & - & - & $\begin{array}{c}0.2^{-} \\
0.6\end{array}$ & - & Balance \\
\hline A-7075 & $\begin{array}{l}2.1^{-} \\
2.9\end{array}$ & $\begin{array}{l}0.2^{-} \\
2.0\end{array}$ & - & $\begin{array}{c}0.18^{-} \\
0.35\end{array}$ & - & $\begin{array}{l}5.1^{-} \\
6.1\end{array}$ & Balance \\
\hline $\mathrm{ACD}-7 \mathrm{~B}$ & - & - & - & - & $\begin{array}{l}4.5^{-} \\
6.0\end{array}$ & - & Balance \\
\hline ACD-12 & - & $\begin{array}{l}1.5^{-} \\
3.5\end{array}$ & - & - & $\begin{array}{l}9.6^{-} \\
12.0\end{array}$ & - & Balance \\
\hline
\end{tabular}

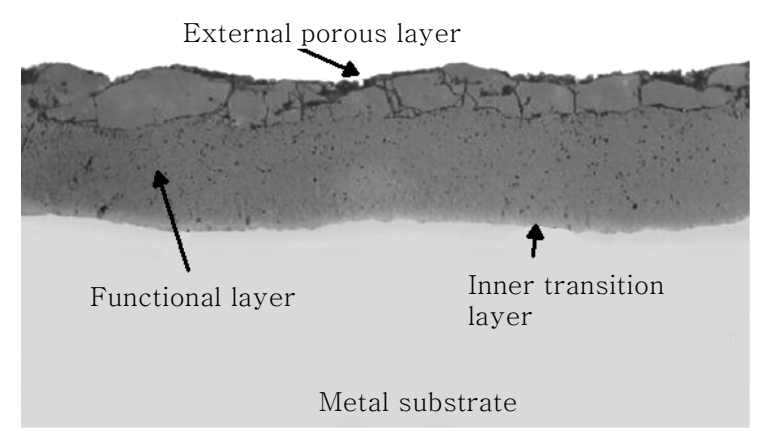

Fig. 3 Layers of oxide formed by PEO treatment on aluminium $^{7)}$ similar main functional layer and transition layer (highly dense, crystalline alumina). A major advantage of the process lies in the fact that the roughness of the coating provided by $\mathrm{PEO}$ treatment is far less than those obtained by other methods such as PVD, CVD, thermal spraying etc. Also, the adherence of the film is much better than that obtained by other methods.

\section{Applications of Plasma Electrolytic Oxidation}

The ability of the PEO process to form a reliable coating on the surface of aluminum will allow it to be used in myriads of applications where the metal's usage was earlier limited due to its low hardness and low corrosion resistance. A thick coating of hard and dense aluminum oxide will prove sacrosanct to the metal's naturally high strength to weight ratio and will push it higher in the rank of engineering materials. It is the next metal of choice with respect to the structural materials, automobile bodies, bicycles and even in the body parts of electronic goods such as mp3 players, laptops and mobile phones. The high dielectric of aluminum oxide also allows it to be used as high grade capacitors, displayed in Fig. 4, and this property is exploited more efficiently after the metal is coated by $\mathrm{PEO}$ process.

A roll of aluminum coated by the PEO process to produce a thick oxide layer on the surface is shown in Fig. 4(a). This coated aluminum oxide is used to manufacture high grade capacitor as displayed in Fig. 4 (b).

Aluminum is almost ubiquitous nowadays; it finds usage from our utensils to our automobiles and a major part of these applications require

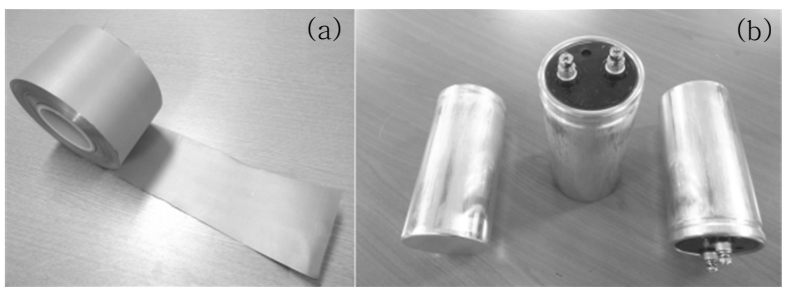

Fig. 4 (a) Aluminium roll coated by PEO process (b) capacitors produced by coated rolls 


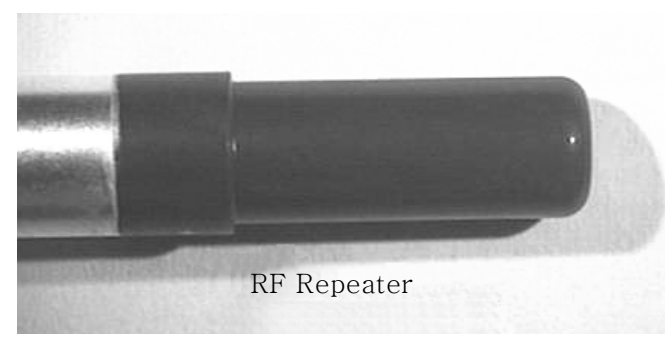

Fig. 5 RF repeater coated by PEO process

a good coating for higher service life with good performance. Other recent uses where PEO plated aluminum is being used include Korean combat rifles ${ }^{10)}$, yacht wenches, driving pulleys and off road sprockets. A RF repeater coated by the PEO process is displayed in Fig. 5.

Another engineering metal with good properties which has not been exploited to its potential because of low corrosion resistance is magnesium. The Pilling Bedworth ratio for magnesium is around 0.8 which sufficiently explains that its natural oxide fails to protect it successfully. To overcome this, sometimes a coating of chromium is applied to enhance the surface properties of magnesium. The hexavalent chromium is recognized as a carcinogen. One advantage of PEO process is the use of environmental friendly electrolytes. The application of PEO to provide a desired coating of magnesium oxide will allow the metal to be used in building light weight automotive body parts and similar other applications. Another application of $\mathrm{PEO}$ on magnesium is in corrosive environments such as the torch used in marine application where weight of equipment plays a vital role in determining the operation and safety of the diver.

Safety issues are of foremost importance when it comes to biological systems. The advancement in medical industries presents opportunities for novel materials to be used in complex biological systems such as the human body. One of the light metals, Titanium, has gained a lot of publicity in the past owing to its increasing use as bio devices. A discovery that titanium binds well to the bone matter introduced it to be used in biological system. However, a major drawback with titanium in this regard is that the naturally protective titanium oxide is thin and might wear out while inside the body and release the metal. Surface treatment of the metal by PEO process might lead to a better oxide film which will allow titanium to be used more as a material for bio devices. Even the oxide of Titanium metal possesses extensive qualities because of which it is used exclusively for a number of applications including the sunscreen, photo catalysts, pigments etc. A proper substrate can be coated with titanium oxide by $\mathrm{PEO}$ treatment to utilize the properties of both titanium oxide and titanium. Apart from these metal systems where PEO treatment finds solo use, it can be applied to systems where composite metal systems are used. One such extensively studied system is the $\mathrm{Al}-\mathrm{Si}$ piston. Scattered studies on other metal systems such as tantalum ${ }^{11)}$, and zirconium are also reported.

\section{Conclusions}

Lighter metals such as aluminum, magnesium etc. suffer a drawback of having low resistance to corrosion and are thus not prevalent in spite of possessing remarkable inherent properties. These metals are mostly put to use only after proper surface treatment. The conventional treatment by anodizing has certain limitations and the film thickness is often not of desired characteristics in some applications. A relatively new surface treatment technology, plasma electrolytic oxidation, overcomes the setbacks of the conventional treatments. The coating provided by this technology is thick, hard, smooth and corrosion resistant. It is known by several other names including micro arc oxidation (MAO), micro plasma oxidation (MPO), plasma chemical oxidation (PCO), plasma anodic oxidation (PAO), anodic spark deposition (ASD), spark discharge oxidation and many others. 
A qualitative comparison of the anodizing process and PEO process, provided at the beginning of the paper clearly brings out the edge the PEO process possesses over the former. An important point to be noted is that the coating provided by $\mathrm{PEO}$ process consists of mostly crystalline alumina compared to the amorphous alumina layer produced by anodizing which makes it prone to cracking. Magnesium, which is often coated with chromium to provide a hard corrosion resistant coating, can be given similar property by growing a PEO film on the surface without the use of carcinogenic hexavalent chromium. Magnesium also has enormous potential to be used in automotive or aircraft bodies with proper surface treatment. However, the most applicable portion seems to be the consumer electronic section where aluminum has found new use as a case for cellular phones, laptops and portable music players. Another metal to which the coating is applied is titanium which is used in critical application such as bio devices. However, the natural oxide of titanium is very thin and is feared to whether away in hostile environments exposing the metal. A thick and uniform coating of titanium oxide can be provided by $\mathrm{PEO}$ treatment in such applications.

Even though, the coating by $\mathrm{PEO}$ is effective and better than their anodized counterparts, these are not perfect in systems such as magnesium. The coating provided by PEO treatment alone might not prove sufficient under harsh conditions since the coating is porous to some extent. These pores are found to be interconnected as pipes to some length ${ }^{3)}$ to the main "functional coating" in some cases and might lead to corrosion. The porosity can be optimized to some extent by controlling the current density. Also, secondary treatment, such as sealing of the coating with a polymer is also possible. However, the PEO technology bears advantage in terms of better performance and surface finish in comparison to the conventional surface treatments. Even though the cost might be a little higher in some case, the higher surface finish and better corrosion resistant properties appear to be advantageous in critical applications involving military and medical devices.

\section{Acknowledgement}

The authors acknowledge the financial support provided by the Seoul R\&BD Program(JP130043)

\section{References}

1. D. A. Becerik, A. Ayday, L. C. K. lu, S. C. Kurnaz, and A. Ozel: The Effects of $\mathrm{Na}_{2} \mathrm{SiO}_{3}$ Concentration on the Properties of Plasma Electrolytic Oxidation Coatings on 6060 Aluminum Alloy, Journal of Materials Engineering and Performance, 21-7 (2012), 1426-1430

2. Y. M. Kim, D. Y. Hwang, W. C. Lee, B. Y. Yoo, D. H. Shin: Surface Modification of High Si Content Al Alloy by Plasma Electrolytic Oxidation, Korean Journal of Metals and Materials, 48-1 (2010), 49-56

3. J.A. Curran, T.W. Clyne: Porosity in plasma electrolytic oxide coatings, Acta Materialia; 54-7 (2006), 1985- 1993

4. http://www.techplate.com.tw/, 05/2014

5. B.Y. Kim, J. G. Kim, D. Y. Lee, M. Jeon, Y. N. Kim, S. Y. Kim, and K. Y. Kim: Effect of $\mathrm{Na}_{2} \mathrm{P}_{2} \mathrm{O}_{7}$ Electrolyte and $\mathrm{Al}$ Alloy Composition on Physical and Crystallographical properties of PEO Coating Layer : I. Physical Properties of PEO Layer, Journal of the Korean Ceramic Society, 49-3 (2012), 241-246

6. H. Duan, C. Yan, and Fuhui Wang: Effect of electrolyte additives on performance of plasma electrolytic oxidation films formed on magnesium alloy AZ91D, Electrochimica Acta, 52 (2007), 3785 - 3793

7. B.Y. Kim, D. Y. Lee, Y. N. Kim, M. S. Jeon, W. S.You, and K. Y. Kim: Analysis of Oxide Coatings Formed on Al 1050 Alloy by Plasma Electrolytic Oxidation, Journal of Korean Ceramic Society, 46-3, (2009), 295-300

8. L. Pezzato, K. Brunelli, S. Gross, M. Magrini, and M. Dabala: Effect of process parameters of plasma electrolytic oxidation on microstructure and corrosion properties of magnesium alloys, Journal of Applied Electrochemistry, DOI 10.1007/s10800-014-0695-x, (2014)

9. W. H. Hua, J. Z. Sun, L. B. Yu, Y. F. Rong, and L. $\mathrm{X}$. Yi: Characterization of microarc oxidation proess on aluminium alloy, China Physics Letters, 20-10 (2003), 1815-1818

10. http://naain.com/eng/applications.html, 05/2014

11. I. Kume, N. Inoue, T. Toda, M. Furumiya, T. Takeuchi, F. Ito, T. Iwaki, S. Shida, and Y. Hayashi: Low Temperature Plasma-Oxidation Process for Reliable Tantalum-Oxide (TaO) Decoupling Capacitors, IEEE, (2008), 225-227 
12. Soodong Park, Sanghoon Yoon, Kicheol Kang, Changhee Lee: Characterization of Ni/YSZ Anode Coating for Solid Oxide Fuel Cells by Atmospheric Plasma Spray Method, Journal of KWJS, 26-4 (2008), $50-54$

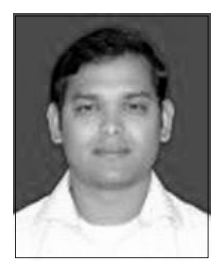

Mukesh Kumar Sharma received the B.Sc. and M.Sc. degrees in metallurgical and materials engineering from the Bengal Engineering and Science University Shibpur and Indian Institute of Technology Kharapur, India, in 2009 and 2013 respectively.

He is a Researcher with the department of Materials Science and Engineering, University of Seoul, Seoul, Korea. His current research interests include science of material joining processes.

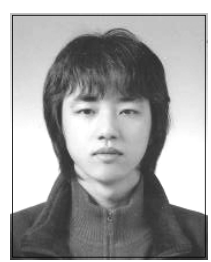

Youngjoo Jang received the B.Sc. degrees in physics from Gachon University, Seongnam, Korea, in 2014, respectively.

He is a Senior Research Engineer with the department of Materials Science and Engineering, University of Seoul, Seoul, Korea. His current research interests include evaluation of electroplating characteristics.

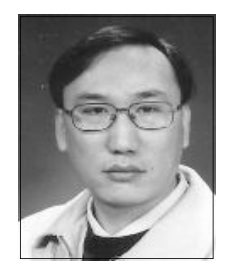

Jongmin Kim received the B.Sc. and M.Sc. degrees in Physics from Chungbuk National University, Cheongju, Korea, in 1988 and 1992, respectively, and the Ph.D. degree in Physics from the Chungbuk National University, in 2001.

$\mathrm{He}$ is a Senior Research Engineer with the APRO R\&D Co., Ltd., Korea. His current research interests include thin film, plasma electrolytic oxidation and metal surface treatment.
13. H. K. Lee, D. H. Kim, S. H. Hwang, B. K. Ahn, B. K. Kim, D. S. Suhr and M. K. Ahn: A Study on the elastic properties of coated layers and the changes of microstructure in plasma spray coating of $\mathrm{Al}_{2} \mathrm{O}_{3}-\mathrm{TiO}_{2}$ ceramics, Journal of KWJS, 14-6 (1996), 109-118

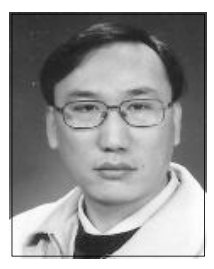

Jongmin Kim received the B.Sc. and M.Sc. degrees in Physics from Chungbuk National University, Cheongju, Korea, in 1988 and 1992, respectively, and the Ph.D. degree in Physics from the Chungbuk National University, in 2001.

$\mathrm{He}$ is a Senior Research Engineer with the APRO R\&D Co., Ltd., Korea. His current research interests include thin film, plasma electrolytic oxidation and metal surface treatment.

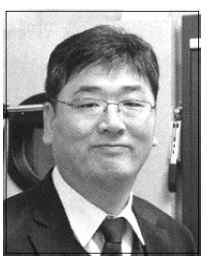

Hyungtae Kim received the B.Sc. and M.Sc. degrees in metallurgical engineering from Sungkyunkwan University, Suwon, Korea, in 1993 and 1996, respectively, and the Ph.D. degree in metallurgical engineering from Sungkyunkwan University, in 2000 .

He is a CEO with the APRO R\&D Co., Ltd., Korea. His current research interests include micro bonding of soldering, failure analysis, reliability testing and plasma electrolytic oxidation

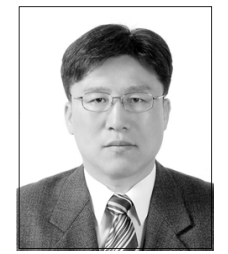

Jae Pil Jung received the B.Sc. degree in metallurgical engineering from Seoul National University, Seoul, Korea, and the M.Sc. degree in materials science and engineering from Korea Advanced Institute of Science and Technology, Daejeon, Korea in 1983 and 1985, respectively, and the Ph.D. degree in metallurgical engineering from Seoul National University, Seoul, Korea, in 1992.

He is a Professor with the University of seoul, Seoul, Korea. His current research interests include microjoining, electronic packaging, electroplating. 